\title{
DA PROXIMIDADE GEOGRÁFICA AO CLUSTER INOVATIVO: UM ESTUDO SOBRE O MODELO BRASILEIRO DE ZONA DE PROCESSAMENTO DE EXPORTAÇÃO
}

FROM GEOGRAPHICAL PROXIMITY TO INNOVATIVE CLUSTER: A STUDY ON THE BRAZILIAN MODEL OF EXPORT PROCESSING AREA

\section{Denio Igor Silva de Pontes}

Doutorando em Administração (Universidade AixMarseille/França). Professor na Faculdade CDL (Fortaleza/Brasil).E-mail: igorpontesce@hotmail.com. 


\section{RESUMO}

Diversos estudos evidenciam a relação positiva entre o grau de internacionalização e o desempenho inovativo de empresas. Nesse sentido, para promover inovações do tipo tecnológicas e, consequentemente, as exportações, alguns estados da federação têm estimulado a formação de aglomerações geográficas de empresas de base exportadora, conhecidas como Zonas de Processamento de Exportação (ZPEs). No Brasil, totalizam 24 projetos, em diferentes fases pré-operacionais e distribuídos em dezoito estados. Assim, este artigo busca identificar os fatores que contribuem para o desenvolvimento de um cluster inovativo a partir de uma aglomeração de empresas baseada em incentivos governamentais. Para atingir o objetivo proposto, buscou-se compreender o modelo brasileiro de ZPEs - a partir de um estudo de caso na ZPE do Pecém (Estado do Ceará). A escolha da ZPE do Pecém reside no fato de ser a primeira e única zona em pleno funcionamento no Brasil. O caminho apontado nesse estudo para a existência de clusters é o da via das interações entre os atores, de modo a promover a partir dessas relações a criação de conhecimento envolvendo os atores locais e, assim, produzir vantagens competitivas sustentáveis para a região.

Palavras-chave: Zonas de Processamento de Exportação. Clusters. Criação de Conhecimento.

\section{ABSTRACT}

Several studies show the positive relation between the degree of internationalization and the innovative performance of companies. In this sense, to promote technological innovations and, consequently, exports, some states of the federation have stimulated the formation of geographical agglomerations of exportoriented companies known as Export Processing Zones (EPZs). In Brazil, there are 24 projects, in different pre-operational phases and distributed in eighteen states. Thus, this article seeks to identify the factors that contribute to the development of an innovative cluster from an agglomeration of companies based on governmental incentives. To reach the proposed objective, we sought to understand the Brazilian model of ZPEs - based on a case study in the Pecém ZPE (State of Ceará). The choice of Pecem's ZPE lies in the fact that it is the first and only zone in full operation in Brazil. The way pointed out in this study for the existence of clusters is the way of interactions between the actors, in order to promote from these relations, the creation of knowledge involving the local actors and, thus, to produce sustainable competitive advantages for the region.

Keywords: Export Processing Zones. Clusters. Creation of Knowledge. 


\section{INTRODUÇÃO}

Alcançar e manter um nível satisfatório de desenvolvimento econômico e social é o objetivo das nações e regiões. Para isso, algumas condições básicas precisam estar consolidadas, tais como: acumulação de capital, desenvolvimento do parque industrial, elevação do nível educacional da população e estabilidade política. Entretanto, durante esse processo de acumulação, os benefícios não são necessariamente repartidos uniformemente entre os territórios nacionais. São justamente essas distorções que justificam a intervenção do Estado como forma de equalizar os efeitos polarizadores.

Na dimensão espacial, sabe-se que países competem com países e, dentro destes, regiões competem com regiões. Nesse contexto de competitividade e de manifesta polarização espacial, cada área geográfica de um país sofre restrições ao seu crescimento caso não se torne competitiva. Para que isto ocorra, essas áreas infranacionais precisam ser dotadas de um conjunto de características fundamentais, que são apresentadas pelas regiões mais desenvolvidas de um país. A ausência de certos atributos, como por exemplo, ativos infraestruturais e capital humano, presentes nas regiões mais ricas, impossibilita as regiões menos desenvolvidas de crescerem economicamente, ou, ainda, de se inserirem ativamente nas cadeias de suprimentos mundiais (GALVÃO, 2010).

Celso Furtado ${ }^{1}$, na segunda metade do século passado, já defendia a tese de que as desigualdades interregionais são consideradas como uma ameaça à coesão social e mesmo, em alguns casos, à unidade nacional. Afinado com essas constatações, estão em curso no Brasil iniciativas que visam suplantar as dificuldades identificadas, em termos de descentralização do parque industrial. Nesse contexto, elegeu-se incentivar a formação de aglomerações espaciais de empresas, seguindo o modelo adotado pelos países do Leste Asiático. Esse modelo ficou conhecido na literatura através do artigo de Lucas (1993) intitulado Making a Miracle (Produzindo um Milagre), onde são apontados os motivos do sucesso desses países e atribui tal feito às políticas de industrialização voltadas para a exportação de bens manufaturados. Essas políticas são denominadas mundialmente de Zonas Francas de Exportação ou Zonas Especiais Econômicas, ou mesmo, Zonas de Processamento de Exportação (ZPE) como ficaram conhecidas no Brasil.

As ZPEs são definidas como distritos industriais incentivados destinadas à atração de empresas exportadoras que oferecem concessões especiais de taxas, tarifas e regulamentações. Essas zonas especiais são

\footnotetext{
${ }^{1}$ Presidência da República, Conselho de Desenvolvimento, Grupo de Trabalho para o Desenvolvimento do Nordeste (GTDN). Uma política de desenvolvimento econômico do Nordeste. Rio de Janeiro: Departamento de Imprensa Nacional, 1959.
} 
caracterizadas por uma concentração de grandes empresas, notadamente, multinacionais que destinam grande parte da sua produção ao mercado externo. A empresa instalada nessa área é exigida que no mínimo $80 \%$ da sua receita seja resultado de suas exportações.

Esse instrumento de política industrial está inserido no processo de globalização, caracterizado pelo aumento de empresas multinacionais, multiplicação do volume de tráfico mundial de mercadorias e expansão das transações financeiras. As inúmeras "deslocalizações" de plantas industriais que esse processo suscitou têm modificado o centro de gravidade da economia mundial, favorecendo os países que compõem os BRICS. Dornier e Fender (2009) destacam que esse fenômeno é essencialmente motivado pela existência de diferenciais de custo de produção nos países e regiões (mão-de-obra, matérias-primas, incentivos fiscais, infraestrutura logística etc.).

Braga (2006) destaca que as ZPEs podem ser consideradas como uma poderosa ferramenta de política de desenvolvimento regional, sobretudo, pela sua capacidade de induzir a descentralização da atividade econômica. Contudo, para que este projeto seja possível e economicamente viável, algumas pré-condições precisam ser atendidas: infraestruturas logísticas, capital humano, tecnologia e aparelho institucional. De fato, os esforços de um país ou de uma região economicamente e socialmente menos favorecida, é de se tornar um polo de atração de investimentos privados.

Dito isso, analisaremos as condições pelas quais uma ZPE implantada dentro de um distrito industrial do tipo identificado nos estudos de Markusen (1996), Brenner (2004) e Visser (2009), - que não apresentam características de clusters - podem contribuir para o desenvolvimento econômico e social de uma região, através da promoção de interações produtivas entre os atores. Utilizaremos como estudo de caso ilustrativo a ZPE do Pecém localizada no estado do Ceará.

Para a consecução desta pesquisa, mobilizaremos as teorias que tratam de aglomeração espacial de empresase sobre criação de conhecimento no seio desses arranjos produtivos locais. O objetivo é identificar os fatores que contribuem para o processo evolutivo de um distrito industrial, em que os atores estão apenas colocalizados geograficamente sem empreender interações e desfrutando apenas de vantagens locacionais ou naturais, até chegar ao nível de cluster inovativo estruturado na forma de rede territorial de organizações interconectadas.

A partir destas primeiras noções, almeja-se ao longo desta pesquisa responder a seguinte questão: uma política industrial concebida na forma de uma ZPE, a partir da atração de fatores exógenos através de incentivos fiscais, pode desencadear processos de interações produtivas entre os atores envolvidos e, com isso, produzir as condições necessárias para criação de conhecimento? 


\section{METODOLOGIA DA PESQUISA}

A pesquisa é de natureza qualitativa e exploratória. A metodologia de pesquisa adotada foi o estudo de caso, com a coleta de dados primários e secundários. O caso abordado nessa pesquisa é a ZPE do Pecém. Para Giroux (2003, p. 43), o estudo de caso é mais indicado para pesquisas que pretendem descrever um fenômeno em toda sua complexidade, de acordo com uma abordagem dita "compreensiva", considerando um grande número de fatores. A investigação começou com uma revisão da literatura com uma busca sistemática de artigos sobre o tema. Eles foram identificados utilizando palavras-chave: zonas de processamento, concentração geográfica de empresas, criação de conhecimento.

Para a coleta de dados primários, realizamos pesquisa de campo. De acordo com Snow e Thomas (1994), a pesquisa de campo é a metodologia que possui o mais alto nível de realismo e, também, a mais difícil de ser controlada. Para David (2000) e Thiétart (2003), esta fase da pesquisa é compreendida como um momento que favorece a emersão dos conhecimentos práticos e teóricos. Os dados foram coletados a partir de pesquisa de campo empreendida no Estado do Ceará, nas cidades: Fortaleza, São Gonçalo do Amarante (distrito do Pecém) e Caucaia. Nas duas últimas cidades está instalado o Complexo Industrial e Portuário do Pecém (CIPP), onde está inserida a ZPE do Pecém. A ZPE foi selecionada devido a sua primazia, ou seja, é a primeira zona de processamento em atividade no Brasil, com indústrias em fase de construção e operação. Como é o caso da Companhia Siderúrgica do Pecém (CSP), com investimentos de US\$ 8,1 bilhões e contando com uma área total de 989 hectares. A CSP é uma joint-venture entre a Vale, Dongkuk e Posco.

Em dezembro de 2012, foram realizadas entrevistas informais com gestores responsáveis pelo porto (empresa Cearaportos) e gestores da Secretaria de Infraestrutura do Estado (Seinfra) com a finalidade de identificar a relevância do empreendimento. Entre os meses de setembro e novembro de 2015, empreenderam-se entrevistas conforme lista disposta no Anexo 1. A amostra selecionada buscou ser coerente com o objetivo do estudo e, com isso, foram selecionados entrevistados possuidores de estatuto hierárquico elevado capazes de fornecer respostas pertinentes à questão de pesquisa (HUBERMAN; MILES, 2003). Foram realizadas nove entrevistas com duração de 55 minutos a 2 horas.

Respeitando os aspectos teóricos e com a ambição de obter maior clareza do fenômeno estudado elaborouse um questionário, conforme Anexo 2. Optou-se pela utilização de questionários semiestruturados, sugerido por Quivy e Van Campenhoudt (1995, p. 163) quando da impossibilidade de entrevistar um número muito grande de pessoas. Todavia, o pesquisador deve garantir a máxima diversidade de perfis através da estratificação amostral. As entrevistas foram gravadas e transcritas na íntegra, codificadas e, em seguida, 
analisadas (BLANC et al., 2014). Os autores afirmam que a principal vantagem deste método é a validade dos dados produzidos. Os dados gerados espontaneamente ou em resposta a questões abertas, são mais propensos a refletirem a realidade.

Para preservar o anonimato dos entrevistados e organizações foram codificadas todas as entrevistas, conforme Anexo 3. Foram construídos os códigos usando as três primeiras letras das duas primeiras palavras de cada cargo/função. Adicionou-se um número caso haja mais de um entrevistado exercendo uma mesma função. Assim, o código "COODEN" foi construído usando as três primeiras letras da palavra "coordenador" acompanhada pelas três primeiras letras da palavra "desenvolvimento", referindo-se à atividade "coordenador de desenvolvimento comercial".

Além desta introdução, este artigo foi estruturado em seis seções. Na segunda e terceira seções, apresenta-se o referencial teórico mobilizado na pesquisa. Na quarta, o caso de estudo selecionado é apresentado: a zona de processamento de exportação do Pecém. Na quinta, analisa-se o caso de estudo fundamentando-se no arcabouço teórico mobilizado e nos dados coletados na pesquisa de campo. Na última seção, são agrupadas as principais conclusões.

\section{ZONAS DE PROCESSAMENTO DE EXPORTAÇÃO}

Em um sistema econômico cada vez mais globalizado, as nações estão cada vez mais integradas, seja no âmbito cultural ou econômico. Tal fenômeno traz como aspectos positivos o aumento dos mercados de bens, serviços e de capitais. Nessa economia, o objetivo almejado ou idealizado pelos países e/ou regiões passa a ser a obtenção de exportações líquidas (exportações menos importações) ou de balança comercial positiva (GREMAUD, 2012), sobretudo, para os países em que o comércio internacional tem participação significativa na composição do PIB. Assim, pode-se falar em superávit comercial.

Os mercantilistas foram os primeiros, historicamente falando, a buscar de forma institucional uma balança comercial favorável, porém, sem nenhuma preocupação desenvolvimentista, visto que seu único interesse era o acúmulo de metais preciosos que se constituía na principal fonte de riqueza das nações. De forma antagônica à globalização, os mercantilistas buscavam uma balança comercial superavitária através do protecionismo como instrumento de proteção do acúmulo de moedas e não como apoio à produção doméstica. Os ganhos do comércio internacional foram evidenciados de maneira mais contundente com a teoria das vantagens comparativas de David Ricardo, que constitui-se na base da Teoria Clássica do Comércio Internacional, e sugere que cada país deve especializar-se na produção daquela mercadoria em 
que é relativamente mais eficiente. Aprimorando a teoria das vantagens comparativas e fortalecendo a ideia dos ganhos mútuos do comércio internacional, a Teoria neoclássica mostra através do modelo de HecksherOhlin que as diretrizes do comércio internacional estarão dadas pela escassez ou abundância relativa de fatores de produção. Com a dificuldade de industrialização de alguns países, surge uma série de teorias que buscam proteger as indústrias nascentes através de tarifas. Após os anos 70, passa a permear no campo da economia internacional a ideia de que a integração entre os países e regiões seria um passo importante rumo ao desenvolvimento (KRUGMAN, 2001).

O benefício de um país ou de uma região fornecer uma quantidade de bens e serviços maior do que a quantidade a qual ele adquire de outros países, é de construir uma poupança interna robusta e, por conseguinte, realizar projetos de investimento. Fato este, tido de grande importância para as nações em desenvolvimento e para as regiões com taxas pífias de crescimento econômico.

É dentro desse contexto que se inserem as ZPEs, permitindo que os países passem a disputar fatias do concorrido mercado globalizado. Estas zonas especiais são caracterizadas por uma concentração de grandes empresas, notadamente, multinacionais que destinam grande parte da sua produção ao mercado externo. A nova ordem mundial chama a atenção dos países em desenvolvimento a se lançarem ao mercado internacional através da atração de grandes conglomerados. Para isso, eles estão dispostos a oferecer infraestrutura logística adaptada, assim como, incentivos fiscais. Essas vantagens respondem aos anseios das multinacionais que buscam reduzir seus custos de produção.

A Organização Mundial do Trabalho - OIT define as ZPEs como "áreas geográficas destinadas à atração de empresas exportadoras que oferecem concessões especiais de taxas, tarifas e regulamentações" (MILBERG; AMENGUAL, 2008). Essas zonas têm por vocação promover as exportações, assim como, modernizar a economia dos países que as implantam. Segundo estudo do Banco Mundial (BIRD, 2008), os objetivos de desenvolvimento foram amplamente atingidos nos países que fizeram uso dessas zonas especiais.

Para Aggarwal (2005), as ZPEs podem ser compreendidas como uma estratégia de integração dos países emergentes com a economia mundial, através das cadeias de produção mundiais. Também são utilizadas para criar empregos, aumentar o valor agregado das exportações, reforçar a balança de pagamentos, absorver novas tecnologias e práticas modernas de gestão. Um ponto em comum entre as zonas especiais espalhadas ao redor do mundo é que, na maioria dos casos, existe uma participação ativa do Estado nos projetos. Muitos desses gestores públicos ensejam desencadear um processo desenvolvimentista por meio da correção de desequilíbrios regionais. 


\subsection{ZPE E AS EXPERIÊNCIAS MUNDIAIS}

Lucas (1993, p. 251-252) indaga sobre as razões do enorme sucesso dos países do Leste Asiático e do relativo fracasso de tantos outros. A resposta a essa questão, segundo o autor, são os seguintes eventos: incentivos às exportações de bens manufaturados, que passam a incorporar quantidades crescentes de capital e de conhecimento; uma atenção especial à educação e ao treinamento da mão-de-obra; criação de um ambiente favorável aos investimentos privados, domésticos e estrangeiros; utilização de política industrial e de políticas de comércio exterior consistentes com o crescimento a longo prazo; boa governança; e assim por diante. São justamente esses fatores que estão por trás do sucesso das ZPEs.

Os países da América do Sul, seguindo as diretrizes da CEPAL, adotaram um modelo de industrialização voltado para a substituição de importações. Exatamente o inverso do que foi posto em prática pelos países asiáticos que adotaram políticas a favor das exportações (KRUGMAN, 2001). Países como Hong Kong, Taiwan, Coréia do Sul, Singapura, Malásia, Indonésia e China observaram que poderiam obter um forte crescimento econômico intensificando o comércio internacional e atraíram investidores desejosos pela liberação imediata de importações de matérias-primas, máquinas e equipamentos destinados à produção de bens exportáveis. Essa política estimulou as exportações, ao mesmo tempo, que não comprometeu a indústria local que precisava de tempo para ser exposta à concorrência estrangeira (KRUGMAN, 2001).

De acordo com Milberg e Amengual (2008), o número de países que utilizam as ZPEs passou de 29, em 1975, para 130, em 2006. Esses 130 países possuíam 3.550 zonas que empregavam 66 milhões de pessoas. A China é indubitavelmente o país que mais faz uso das zonas econômicas especiais.

Através das experiências mundiais é possível identificar que para alcançar o sucesso esperado são necessárias, dentre outras medidas, promover as relações das ZPE com o resto da economia. Na ausência dessas interações ou não havendo uma perfeita interação entre os atores, a ZPE pode não produzir êxito. E para isso, é preciso atender a alguns pré-requisitos:

- a forte atuação do governo implantando políticas coerentes de atração de empresas, investindo na qualificação da mão-de-obra, objetivando a absorção tecnológica;

- o domínio das empresas nacionais fornecedoras, dos modernos processos de gestão e a utilização de tecnologia da informação;

- os esforços das entidades públicas e privadas situadas fora das zonas, oferecendo apoio e acompanhando os níveis de desempenho das empresas incentivadas. 


\subsection{AS ZPES NO BRASIL}

A ZPE é um distrito industrial incentivado, no qual indústrias nele localizadas operam com benefícios tributários cambiais e administrativos. Pela legislação brasileira, no mínimo 80\% da sua receita devem ser resultados de suas exportações. A história das ZPEs no Brasil foi marcada por inúmeras questões de interesses políticos e econômicos, entre os industriais do Sul e Sudeste, sobretudo, São Paulo, e os defensores de um modelo de desenvolvimento industrial para o país fundamentado em uma lógica de descontração espacial. Mesmo assim, em 1988, a primeira lei foi criada e 17 projetos foram implantados. Todavia, os Estados ficaram aguardando uma autorização federal para começarem a funcionar, a qual não foi concedida (BRAGA, 2006).

Fazendo uma comparação, em 1988 a economia chinesa já contava com 15 zonas econômicas especiais e sua economia era semelhante à brasileira. Dez anos depois, a China possuía 167 zonas, enquanto o Brasil só tinha a Zona Franca de Manaus, criada em 1967 para atender as multinacionais fabricantes de produtos destinados ao mercado interno (VIANNA, 2010). Atualmente, o Brasil conta com 24 projetos, de acordo com a Associação Brasileira de Zonas de Processamento - ABZP. Dentre eles, a ZPE do Pecém localizada na região Nordeste do país, no Estado do Ceará. A primeira e única ZPE em operação no Brasil.

O Brasil conta com um importante fator de produção, que é possuir abundância de matérias-primas no território nacional. Esse fato abre uma janela de oportunidades para as empresas e capacita as ZPEs brasileiras a se tornarem centros mundiais de tratamento e processamento de matérias-primas. Atualmente, o perfil da economia brasileira ainda é a exportação bruta, ou seja, a venda de produtos com baixo valor agregado.

Braga (2006) destaca que o Brasil possui a taxa histórica de apenas 1\% do mercado mundial, não fazendo jus, assim, ao tamanho da sua economia. Essa constatação justifica a importância das ZPEs para o país, uma vez que, a única forma de participar ativamente do mercado internacional é através de políticas de exportação consistentes e planejadas.

De acordo com a legislação, os incentivos concedidos às empresas instaladas em uma ZPE nas importações e nas compras no mercado interno de equipamentos, insumos e maquinários, são os seguintes:

- Imposto de importação

- Adicional de frete para renovação da Marinha Mercante (AFRMM)

- Suspensão dos tributos IPI, COFINS e PIS/PASEP

- FINSOCIAL

- IOF 
Além desses, para as empresas que se instalarem no Norte e Nordeste, conforme lei sancionada, há 75\% de redução do IR. Além disso, as empresas gozarão de liberdade cambial (não precisam fechar câmbio) e de procedimentos administrativos mais simplificados; e os tratamentos fiscal, cambial e administrativo serão assegurados pelo prazo de até 20 anos, que poderão ser prorrogados.

\section{CONCENTRAÇÃO ESPACIAL DE EMPRESAS}

Dentro do contexto localização geográfica em que as políticas industriais de alocação das ZPEs se inserem, destacamos o caráter intrínseco dessa política com o território em que está inserida. Assim sendo, destacamos que o poder econômico de uma região é determinado pela existência de fatores de produção, tais como: acesso ao mercado de capitais e de informação, facilidades logísticas, conexões internacionais, acesso ao mercado de matérias-primas, recursos humanos com alta qualificação etc. O conjunto desses fatores determina a vantagem comparativa de uma região, seu lugar numa rede mundial e o espaço econômico que ela controla. As fronteiras de uma região flutuam em função de sua vitalidade econômica. Mais que um simples lugar geográfico, o território tende a tornar-se uma importante fonte para as organizações (GIPOULOUX, 2000; PORTER, 1990, 1998).

O acesso e o provimento desses fatores de produção geram uma competitividade entre os países e também entre as regiões. Essa busca por igualdade entre as regiões tem influenciado a emergência de estudos sobre desenvolvimento regional. As principais tendências dessa teoria estão ligadas à competitividade e à organização da indústria local. Essa corrente teórica destaca as vantagens competitivas da indústria local, em particular as estruturas que praticam o reagrupamento espacial de empresas. Em 1920, Marshall (1988) reconheceu as vantagens de ter uma "indústria localizada", termo utilizado pelo autor para caracterizar esse comportamento. O autor observa que essa mudança de comportamento das empresas foi inicialmente influenciada por aspectos físicos da época, tais como, condições climáticas e de solo, proximidade do mercado de matérias-primas e/ou devido a questões logísticas de escoamento da produção aos mercados consumidores.

Marshall defende que empresas localizadas em uma mesma região geográfica tem uma imensa vantagem quando comparadas a outras empresas que não praticam essa estratégia de reagrupamento. Assim, a abordagem do distrito industrial é fundamentada essencialmente sobre o estudo da importância das 
externalidades positivas que, por sua vez, favorecem o aparecimento de economias externas ${ }^{2}$ advindas da proximidade dos atores no processo de produção.

Ainda de acordo com Marshall, o distrito industrial foi identificado como uma estrutura organizacional de produção que executa e desenvolve suas operações sob a forma de cadeia de produção local, reconhecendo assim, os benefícios de uma integração vertical da produção. Esse sistema de produção permitiu a criação de fluxos de conhecimento, especialização da mão-de-obra e um impulso ao dinamismo dos mercados. Estes três fenômenos são estreitamente associados aos processos de produção e contribuem na redução dos custos de produção e na elevação da capacidade de inovação das empresas (SCHUMPETER, 1988).

Becattini (1979 apud DAUMAS, 2007) fez uma releitura do conceito marshalliano de distrito industrial que permitiu unificar progressivamente esse campo de pesquisa heterogêneo. Assim, definiu distrito industrial como sendo uma entidade sócio-territorial caracterizada pela associação ativa, em uma área territorial circunscrita e historicamente determinada, de uma comunidade de pessoas e de indústrias. A diferença nesse sistema de produção é que a comunidade e as empresas tendem a se interpenetrar. Esta definição revela o caráter imbricado da relação entre empresas e comunidade local, ao mesmo tempo em que explicita a dinâmica do distrito. A diferença dessa abordagem suscitada por Becattini é que, de puramente econômico, o conceito de distrito torna-se socioeconômico.

Garofoli (2002) segue na mesma linha de raciocínio e defende que, através dos distritos industriais, o processo de desenvolvimento adquiriu características definitivas de processo social. O autor identificou duas variantes para os distritos industriais marshallianos, ambas respeitando as características de concentração espacial: i. sistema de produção de grande escala (verticalizado) e com fortes relações hierarquizadas; ii. sistema de pequenas empresas não submissas a relações hierarquizadas, mas a práticas de cooperação.

Daumas (2007) sintetiza as várias definições sobre distrito industrial e obtém uma descrição ampla que associa os tratados seguintes:

- especialização em um setor específico exigindo mão-de-obra qualificada;

- aglomeração de empresas ligadas entre elas por relações de concorrência e cooperação;

- economias externas oriundas da proximidade geográfica;

\footnotetext{
${ }^{2}$ As economias externas são definidas como os ganhos obtidos pela firma independente de suas ações. Como exemplo, podemos citar a oferta de infraestruturas, mão-de-obra qualificada, recursos naturais, tecnologia de informação, além de relação interempresariais sólidas, dentre outras. Para Schmitz (1997), as economias externas quando associadas às ações conjuntas "jointsaction”, produzem uma vantagem concorrencial que ele denomina de "eficiência coletiva".
} 
- atmosfera favorável ao aprendizado e à inovação;

- forte consenso social e instituições parceiras.

O conceito criado por Marshall suscitou a aparição de diferentes conceituações sobre concentração espacial de empresas como, por exemplo: cluster, reagrupamento industriais, distritos industriais, redes, cadeia de suprimento (supply chain), arranjos produtivos locais, dentre outros. Cada sistema de produção mencionado tem características heterogêneas que lhes são próprias.

Apropriando-se dos conceitos desenvolvidos por Garofoli (2002) e Daumas (2007) no que concerne ao caráter socioeconômico que as aglomerações empresarias passaram a desenvolver, fundamentado, prioritariamente, nas interações entre os atores e, destes, com o ambiente que os circunda. A partir dessa base conceitual, busca-se traçar um fio condutor entre a contribuição das interações produtivas, entre atores situados em uma ZPE, para o processo de criação de conhecimento. Desta forma, elege-se mobilizar as teorias que tratam das especificidades do sistema de clusters para o processo de criação de conhecimento.

\subsection{CLUSTER}

A estratégia de cluster é dividida em duas correntes teóricas: uma tendência "marshalliana" e outra tendência "porteriana". Para Porter (1998) ${ }^{3}$, os clusters se definem como concentrações geográficas interconectadas de empresas e instituições. Porter defende a hipótese de que o ambiente exterior tem um papel essencial para a sustentabilidade das empresas. O modelo de cluster destaca como as instituições podem contribuir para o sucesso das empresas e como o Estado pode contribuir para o desenvolvimento econômico (GARCIA; COSTA, 2005). As universidades, as instituições reguladoras, os centros de pesquisa e as associações profissionais e comerciais são igualmente atores ativos nesse modelo.

Segundo Amaral et al. (2002), a estratégia de clusters vista pela corrente "porteriana" procura recuperar certas concepções, tais como:

- articulação sistêmica da indústria com ela mesma, com o ambiente externo, com as infraestruturas logísticas, assim como, com as instituições públicas e privadas, com o objetivo de maximizar a absorção de externalidades, em particular, tecnologia;

\footnotetext{
${ }^{3}$ Porter inseriu a variável território na corrente predominante que trata de políticas regionais, redesenhando todo o conjunto de políticas públicas sobre essa temática. Definiu cluster da seguinte forma: "um cluster é um grupo geograficamente próximo de empresas interconectadas e de instituições associadas, em um domínio particular, ligadas por pontos comuns e complementares” (PORTER, 1998).
} 
- forte associação entre a indústria e atores locais, permitindo ajustes rápidos face a mudanças no mercado;

- vocação ao exterior, em busca constante de competitividade no mercado internacional.

O conceito de clusters vem sendo trabalhado ao longo dos anos, apresentando algumas variantes e focos. Desde os trabalhos de Marshall sobre a indústria têxtil na Inglaterra, passando pelos trabalhos de Becattini (1981) sobre distritos industriais italianos, até chegar aos trabalhos de Porter (1990). Mais recentemente, o conceito de clusters passou a ser mobilizado e desenvolvido pelos pesquisadores em gestão estratégica de inovação (LAURIOL et al., 2008).

Essa evolução na abordagem tem se revelado nas pesquisas que dizem respeito à natureza dos clusters: de uma abordagem relativamente estática, focada prioritariamente nos fatores de sucesso dos territórios, para pesquisas direcionadas no sentido das interpretações dinâmicas fundamentadas nas interações sociais efetuadas entre os atores. Essas interpretações dinâmicas dos processos de interações adotam uma abordagem combinatória da criação de conhecimento como sendo resultante das trocas e combinações de saberes (NAHAPIET; GOSHAL, 1998; KOGUT, 2000).

De acordo com o estudo empírico realizado sobre clusters nos Estados Unidos, Markusen (1996) constatou que existem aglomerações constituídas de estruturas industriais tradicionais, apoiadas pelo Estado e dominadas prioritariamente por grandes empresas, cuja matriz, assim como o capital, encontra-se externamente. Segundo o pesquisador, essas empresas, ou não se beneficiam, ou se beneficiam muito pouco das interações com o meio ao qual estão instaladas.

Dentro desse contexto, Visser (2009) chama a atenção para o fato de que as aglomerações geográficas de empresas não formam sistematicamente clusters. Existem inúmeros exemplos de aglomerações sem interações entre seus membros. As concentrações de atividades econômicas podem também, como destaca Brenner (2004), advir de vantagens ao nível de recursos naturais ou de infraestruturas logísticas, onde as empresas decidem relocalizar suas unidades produtivas por fatores favoráveis e puramente exógenos.

Parte-se do pressuposto que o objetivo de um cluster deve ser dotar uma região de vantagens competitivas sustentáveis, então, presume-se, que somente através da interação entre os atores e, consequentemente, através da criação de conhecimento e inovação é que esse processo poderá se materializar.

\subsection{CRIAÇÃO DE CONHECIMENTO EM AGLOMERAÇÃO DE EMPRESAS}

Neste ponto, destacam-seos trabalhos que buscam aportarao conceito de clusternovossubsídios: abordagens que estabelecem valor à dimensão territorial no que tange à criação de conhecimento e inovação. De acordo 
com esse quadro, pesquisadores da área de gestão de processos de inovação, destacam que a principal vantagem de um cluster reside nos benefícios advindos das interações, que podem propiciar a criação de conhecimento e consequentemente a inovação (MALMBERG; MASKELL, 2002; RYCHEN; ZIMMERMANN, 2006).

Segundo Jayanthakumaran (2003), a utilização eficaz dos clusters como um instrumento de industrialização e de inovação necessita da disponibilidade de relações com o resto da economia. Markusenet et al. (1986) também afirma ao longo de seus estudos que é a intensidade dos vínculos das empresas com a comunidade local que determina a extensão e a dinâmica do desenvolvimento de um cluster. Entretanto, nem sempre é possível verificar interações entre os atores de um cluster, principalmente em países em desenvolvimento (MILBERG; AMENGUAL, 2008; VIRGILL, 2009). O Brasil é um bom exemplo para ilustrar essa assertiva. A questão das interações entre as empresas multinacionais e grandes empresas nacionais com os atores locais está no centro do debate, principalmente nas regiões mais pobres da Federação, como o Estado do Ceará, onde localiza-se a ZPE selecionada para estudo.

Nahapiet e Ghoshal (1998) foram os primeiros a ressaltar que o processo de criação de conhecimento é antes de tudo um processo social. Partindo do pressuposto de que os clusters favorecem as relações informais, Malmerg e Power (2005) destacam vários trabalhos que analisam os clusters não simplesmente como uma aglomeração de empresas relacionadas, mas, sobretudo, sob o ângulo de aglomeração de indivíduos, de competências especializadas e de empreendedores. Segundo esses autores é, portanto, a atenção sobre os indivíduos no seio dos clusters que permite analisar os intercâmbios de conhecimentos.

A inovação é reconhecida como um fator essencial de competitividade para as empresas. Com efeito, as empresas deveriam ser incentivadas a colaborar a nível local objetivando inovar, e assim, compensar suas fraquezas em termos de disponibilidade de recursos (HUET; LAZARIC, 2004; BOISSIN et al., 2011). Alguns trabalhos destacam o papel fundamental desempenhado pelo território na inovação das empresas, reatando-se assim com a noção de cluster de Porter (1998).

Nesse contexto, os trabalhos sobre clusters destacam o importante papel da organização de redes territoriais, dentro das quais se desenvolvem mecanismos propícios à criação de conhecimento (MALMBERG; MASKELL, 2002; GERTLER, 2003). Nesse ambiente, nascem os polos de competitividade na Europa, que se traduzem no desejo de redefinir as políticas industriais e tecnológicas, e de focalizar-se na inovação e nos territórios. Segundo Chesbrough (2003), os polos não visam unicamente favorecer as trocas de conhecimento, eles contribuem mais amplamente para promover os projetos de inovação colaborativos. Isto quer dizer, a combinação de conhecimentos no âmbito de projetos multi-atores (open innovation ou innovation ouverte). 
No seio da escola marshalliana, a abordagem de milieux innovateurs (AYDALOT, 1986) elaborada pelo GREMI (Grupo de Pesquisa Europeu sobre Ambientes Inovadores - sigla em português) concentra-se sobre o papel da especialização e dos processos de aglomerações. Considera-se que esses conceitos fornecem um quadro institucional e cognitivo que estimula a inovação. O GREMI defende as redes de inovação local, mas também as redes de maior amplitude, enfatizando a importância das ligações exteriores ao meio que permitem aos atores assimilarem novas idéias (CAMAGNI, 1991).

As escolas Regional Innovation Systems (RIS) e Learning Region têm em comum, a aplicação de princípios de coordenação institucional oriundos da literatura que trata de sistemas de inovação. De acordo com a escola Learning Region, os clusters podem ser considerados como ferramenta de desenvolvimento econômico, visando criar sinergia entre as empresas locais, e facilitando os mecanismos de transmissão de conhecimento. Esta literatura se concentra prioritariamente na natureza e no papel das instituições, na criação de conhecimento e nos mecanismos que facilitam a absorção desse conhecimento pelas empresas locais (MORGAN, 1997). A necessidade de se manter competitivo impôs à gestão de inovação a contínua missão de criação de conhecimento (TSOUKAS, 1989). Assim, as empresas têm sido obrigadas a conservar suas vantagens competitivas, considerando as constantes evoluções dos ambientes em que estão inseridas (TEECE et al., 1997).

Paralelamente, Cooke (2001) desenvolve o conceito de Regional Innovation Systems. O autor defende a criação sistemática de conhecimento, que segundo ele, é da interação fecunda entre universidades, instituições locais e empresas que se situa o sucesso do processo de inovação. Esta abordagem, procura relacionar a temática da inovação tecnológica a políticas de desenvolvimento regional, apoiando-se no conceito de gestão territorial e de articulação em nível de governança (local/global).

Retomamos os trabalhos de Porter (1990; 1998) para confrontá-los com as teorias que tratam de sistemas "autoorganizados". Autores desta corrente refutam a questão dos fatores-chave de sucesso defendida por Porter. De acordo com essa teoria, fatores de sucesso combinados à proximidade geográfica não são uma condição suficiente para inovar (GARNSEY; LONGHI, 2004). Alguns trabalhos procuram demonstrar que a associação efetiva de conhecimentos não pode depender unicamente da proximidade geográfica. É uma variável necessária, mas insuficiente para ativar a inovação a nível local. Os trabalhos que tratam desse campo de pesquisa são oriundos particularmente da école des proximités (RALLET; TORRE, 2005; BOSCHMA, 2005).

Segundo a école des proximités, se existe no seio de um cluster uma coordenação motivada pela proximidade geográfica, está sozinha não pode contribuir para uma dinâmica de inovação, visto que, existem outras dimensões a serem consideradas (cognitivas, tecnológicas etc.). Loilier (2010) sublinha igualmente a 
dualidade da proximidade: ao lado da proximidade espacial, existe um conjunto de proximidades de natureza não espacial, agrupadas sob o termo de "proximidade organizada"4. Cabendo, portanto, a essa proximidade acompanhar e ativar a proximidade geográfica, para que haja no seio das organizações ou dos territórios interação entre seus membros (RALLET; TORRE, 2005).

A partir das teorias mobilizadas, analisar-se-á as possibilidades que poderão ser criadas pelas Zonas de Processamento de Exportação, mais precisamente a ZPE do Pecém, em termos de desenvolvimento sustentável através do enraizamento na região do conhecimento produzido localmente de forma colaborativa.

\section{CASO DE ESTUDO: ZPE DO PECÉM}

A ZPE está inserida na área do CIPP que foi idealizado para incorporar a função portuária e industrial, voltado para o desenvolvimento do parque industrial do Ceará e de sua área de influência regional, a partir da implantação de projetos-âncora. Nesse sentido, um dos eixos estratégicos do CIPP foi a construção de um terminal portuário, cuja retroárea compreenderia espaços destinados para funcionar como Zona de Processamento de Exportação (ZPE), bem como outras áreas para atração de grandes empreendimentos. Desta forma, configura-se como uma infraestrutura caracterizada pela integração porto indústria.

Apoiado no porto do Pecém, o complexo desenhado ao seu redor objetiva abrigar empreendimentos estruturantes. Dada a extensão territorial do CIPP, sua área abrange dois Municípios do Estado do Ceará: Caucaia e São Gonçalo do Amarante. O CIPP tem 13.337 ha, destinados à implantação de indústrias e empresas prestadoras de serviços. Essa área encontra-se inserida em uma área maior de $335 \mathrm{~km}^{2}$ considerada de utilidade pública. Dessa área do CIPP, 2.340ha são Áreas de Preservação Permanente (APPs) e 109ha destinadas ao Jardim Botânico de São Gonçalo do Amarante. Esses dois municípios fazem parte da Região Metropolitana de Fortaleza (capital do Estado do Ceará), a qual conta com 13 municípios e uma população estimada no ano de 2008 em 3.517.375 habitantes, conforme IBGE. A ZPE situa-se há, aproximadamente, 50 km da Capital Fortaleza.

No ano de 2004 o governo do Estado do Ceará decidiu transferir do município de Maracanaú para o município de São Gonçalo do Amarante a ZPE do Ceará. A ZPE do Pecém foi aprovada por decreto presidencial em 2010. Ela está

\footnotetext{
${ }_{4}^{4}$ A "proximidade organizada" tal como é compreendida pela "escola de proximidades" é essencialmente relacional e responde a duas lógicas: a "lógica de pertencimento", que significa pertencimento a uma organização, onde suas rotinas possibilitam a interação entre seus membros; e a "lógica de similitudes", que quer dizer, a partilha de um mesmo sistema de representações e de crenças. Essas duas lógicas são ao mesmo tempo: complementares, pois como os atores compartilham de interpretações semelhantes terão menos divergências com as regras e, por consequência, a coordenação será melhor conduzindo; e substituíveis, pois a fraqueza das regras pode ser compensada pela existência de coesão comportamental e convergência de representações.
} 
inserida dentro de uma zona devidamente delimitada e dedicada a empresas que destinarão, prioritariamente, sua produção ao mercado internacional. Para gerir esse empreendimento o governo do Estado do Ceará criou a Empresa Administradora da Zona de Processamento de Exportação do Pecém S.A. (EMAZP).

Na área logística, a ZPE se beneficia da multimodalidade de transporte que há no Complexo. Dentre os modais, podemos citar o portuário, o ferroviário, o rodoviário e um sistema de correias transportadoras de matériasprimas. A zona econômica especial também se beneficiará da localização estratégica no território brasileiro, estando a seis dias da costa americana e a sete dias da Europa por via marítima. Esse diferencial locacional permitirá às empresas instaladas na ZPE reduções nos custos de transporte. Entretanto, modernizações e ampliações nos berços de atracação e nas retroáreas precisam ser realizadas para que o tempo de espera dos navios diminua. Outro ponto logístico que carece de melhoria são as conexões ferroviárias capazes de aumentar a área de influência da ZPE no continente.

Assim como o resto do país, o Nordeste brasileiro é também rico em matérias-primas. A região tem vocação para o agronegócio (produção e exportação de frutas, flores e frutos do mar). Dados da Agência de Desenvolvimento do Ceará (Adece) revelam que em 2011, 47\% das exportações de frutas brasileiras (102,5 milhões de dólares) passaram pelo Ceará. Considerando que essas exportações são praticadas com produtos in natura, pode-se vislumbrar para a ZPE do Pecém, a implantação de empresas que adicionem valor aos produtos exportáveis e, por conseguinte, ampliem a taxa de mark-up.

Outra área promissora para o desenvolvimento de cadeias de produção na região é o setor de energias renováveis, como a energia eólica, energia térmica e energia solar. De acordo com a Associação Brasileira de Energia Eólica (Abeeólica) e a Agência Nacional de Energia Elétrica (Aneel), o Estado do Ceará é o produtor de energia eólica que possui a maior cadeia de produção do país.

A disponibilidade de matérias-primas (calcário e minério de ferro) para a indústria siderúrgica influenciaram a criação de uma usina siderúrgica no Estado do Ceará. A Companhia Siderúrgica do Pecém (CSP) é a primeira empresa a se instalar em uma ZPE no Brasil. Segundo fontes do governo do Estado, quando em plena operação, estima-se que a siderúrgica irá alavancar em 48\% o PIB industrial do Estado. É uma empresa pivô que provoca desdobramentos tanto a jusante como a montante na cadeia de suprimentos do setor.

Os impactos esperados pela ZPE do Pecém são: modernização das práticas de gestão; qualificação da mãode-obra; desenvolvimento de relações entre as empresas multinacionais e fornecedores e prestadores de serviços locais; absorção tecnológica; criação de cadeias de produção; desenvolvimento local e regional. 


\section{ANÁLISE DO CASO}

Segundo a teoria econômica neoclássica, iniciativas como a das ZPEs constituem uma opção de segunda ordem, consistindo em compensar a supressão de uma distorção (taxa de importação) com a introdução de outra (incentivos fiscais). Outro ponto contestado, segundo DIRASS-1, é que as empresas estrangeiras têm liberdade cambial para repatriar seus fundos, representando uma fonte importante que poderia ser investida ou servir a modernização social. Apesar dos entrevistados COODEN, DIRCOM, SERDEN, DIRINF não concordarem com essa posição, destacando que os ganhos obtidos em termos de geração de empregos diretos e indiretos (contratação de fornecedores) e externalidades geradas são superiores às perdas fiscais.

Acrescenta-se o fato dos transbordamentos tecnológicos em direção à economia local serem raros, haja vista, a tecnologia e o conhecimento serem integrados ao capital importado, como bem frisou DIRASS, ou seja, os postos de trabalho que demandam melhor qualificação não são preenchidos por moradores locais e nem do Estado. Assim, nos exemplos de produção de tecnologia de ponta em ZPEs, observou-se que essas zonas formam enclaves, onde a única interação com a economia é emprego de alguns trabalhadores locais com elevado nível de qualificação (MILBERG; AMENGUAL, 2008).

As experiências mundiais sugerem que as vantagens proporcionadas pela implantação das zonas especiais estão relacionadas com o grau de integração com a economia local (BANCO MUNDIAL, 2008). As experiências exitosas não podem ser consideradas uma regra e nem muito menos consenso entre os pesquisadores. Os exemplos de sucesso indicam que são provavelmente as instituições e as atividades fora das ZPE que fazem a diferença em termos de sucesso esperado (JAYANTHAKUMARAN, 2003). Nesse contexto, ao entrevistar DIRCOM e SERDEN, agentes públicos responsáveis diretamente pela gestão da ZPE do Pecém, ficou evidenciada a inexistência de projetos de interação produtiva e colaborativa entre as empresas situadas na ZPE e as Universidades localizadas no Estado. Em outras palavras, a questão da produção de conhecimento não é incorporada nas negociações com as empresas atraídas. Fato que reflete a inexistência de um projetoterritório.

Segundo Milberg e Amengual (2008), as relações com a economia local são mais estreitas desde que o Estado seja mais intervencionista e empenhado no desenvolvimento econômico do território. Desta forma, esperase que o Estado implante uma política industrial objetivando fomentar e estimular progressivamente a capacidade de absorção tecnológica das empresas locais. No entanto, identificamos ausência dos agentes públicos estaduais exercendo este empenho. DIRCOM diretor da empresa Companhia Siderúrgica do Pécem, ressalta que na ausência de programas de qualificação de mão-de-obra e fornecedores, coube à empresa 
empreender capacitações. Para isso, a empresa contratou consultorias para desenvolver projetos, gerenciar e executar parcerias com órgãos estaduais e federais para treinar fornecedores locais e trabalhadores. Os agentes públicos DIRCOM, SERDEN, DIRINF e SERDEN ressaltaram a iniciativa positivamente, contudo, não destacaram a omissão do Estado.

Os teóricos ressaltam que é responsabilidade dos gestores das ZPEs fazer fluir em direção à economia local e nacional, os ganhos em termos de competências e tecnologia. Entretanto, para que isso ocorra, as empresas locais e nacionais precisam desenvolver habilidades no campo da gestão para candidatar-se como fornecedoras ou prestadoras de serviço, num primeiro momento. DIRASS e PREASS lembram que as empresas locais não possuem um nível mínimo de gestão, tecnologia e organização contábil que permita interagir com as grandes empresas instaladas na ZPE. Desta forma, pode-se inferir que dificilmente ocorrerá no sei da ZPE do Pecém processos de criação de conhecimento colaborativo entre os atores lá instalados e a comunidade do entorno. Ademais, vale ressaltar, que as empresas multinacionais possuem a inclinação a manter seus fornecedores estrangeiros, por questões de qualidade, confiança, além de compartilharem conceitos modernos de supply chain management.

Assim, o objetivo é de absorver tecnologia e expertise e, em seguida, passar a um estágio mais avançado de produção, ou seja, passar da fase de "montador de manufatura", para a fase de desenvolvedor local das etapas mais avançadas do processo de produção, que são justamente as que agregam mais valor aos produtos, como por exemplo, P\&D, marketing, designer, e, assim, internalizar todos os ganhos produtivos.

Com isso, um maior número de etapas do processo produtivo seria concebido na própria área da ZPE ou em seu entorno, abrangendo as fases de concepção e projeto (a montante na cadeia) e, logística de distribuição (a jusante na cadeia). A etapa de criação e produção de bens manufaturados originais consubstancia o sucesso de uma ZPE. Esta é uma ambição, ainda longínqua para a ZPE do Pecém, sobretudo, por não ser uma perspectiva nem vislumbrada pelos gestores públicos, como destacou DIRASS-1.

Em última análise, o objetivo de uma ZPE deveria ser a endogeneização da cadeia de suprimentos. O foco é atrair atividades realizadas a priori fora da ZPE, atividades essas relacionadas com a produção de conhecimento e inovação, emponderando-se e enraizando o savoir-faire produtivo e criando, assim, vantagens competitivas sustentáveis inter-relacionadas com território. Desta forma, contrapor-se-ia, com a busca de vantagens não sustentáveis, também ditas momentâneas, ancoradas na mobilidade do capital e na geração de emprego de baixa remuneração. Esta última, foi a tendência verificada na ZPE do Pecém. 


\section{CONSIDERAÇÕES FINAIS}

De acordo com as abordagens conceituais de clusters, pôde-se constatar que a ZPE do Pecém é fundamentada em abordagens relativamente estáticas, focalizadas prioritariamente nos fatores-chaves de sucesso do território, caracterizados pelas externalidades econômicas. Podemos identificar na ZPE as seguintes características: aglomeração constituída de estruturas industriais tradicionais, apoiadas pelo Estado e dominados prioritariamente por grandes empresas, cuja matriz como o capital encontra-se externamente. Consequentemente, as decisões estratégicas de investimento provêm do exterior. Desta forma, essas empresas dificilmente irão empreender cooperações com o meio ao qual estão inseridas.

AZPE do Pecém é engendrada pela atratividade de fatores exógenos, não distando nem das demais iniciativas brasileiras de industrialização, nem das muitas experiências mundiais, principalmente em curso pelos países emergentes. Aos gestores públicos do Estado do Ceará, cabe compreender que esta fase deve ser planejada para que possa ser suplantada no médio e longo prazo. Para isso, a meta deve ser o desenvolvimento endógeno - baseado no apoio às forças econômicas e sociais locais e nas interações produtivas entre os atores.

O cálculo do custo-benefício social não pode ficar à margem das tomadas de decisões governamentais. As ZPEs provocam um impacto positivo imediato no emprego e no IED. De outra parte, os benefícios das ZPEs devem ser avaliados levando em consideração seus custos intrínsecos, principalmente as perdas de rendas fiscais e tarifárias. Por isso, é responsabilidade das instituições de fomento fazer essas ponderações, com vistas no longo prazo. Todavia, vale salientar que não faltam registros de casos em que o território se revela um elemento matricial da vida coletiva (Silicon Valley, a Finlândia, a Itália dos distritos industriais marshallianos, constam entre os múltiplos exemplos), ressaltando o caráter positivo da proximidade e a geração de formas de eficiência coletiva na produção de tecnologia e inovação.

Deste modo, para que a ZPE do Pecém obtenha o sucesso esperado, é imprescindível que a região disponha do fator de produção capital humano melhor qualificado. O Governo do Estado tem empreendido esforços nesse sentido, entretanto, as iniciativas são incipientes frente às exigências e necessidades que se impõe.

O caminho apontado nesse estudo é o da via das interações entre os atores, De modo a promover a partir dessas relações a criação de conhecimento envolvendo os atores locais e, assim, produzir vantagens competitivas sustentáveis para o território. Este esforço visa alcançar um nível satisfatório de empoderamento local, que possibilitará uma "independência econômica" regional das deliberações unilaterais das empresas multinacionais. 


\section{REFERÊNCIAS}

AGGARWAL, A. Performance of export processing zones: A comparative analysis of India, Sri Lanka and Bangladesh. Indian Council for Research on International Economic Relations, 2005.

AMARAL FILHO, J. et al. Núcleos e Arranjos Produtivos Locais: casos do Ceará. Rede de Pesquisa em Sistemas Produtivos e Inovativos Locais. Universidade Federal do Rio de Janeiro, 2002.

AYDALOT, P. Milieux innovateurs en Europe. Paris, GREMI, 1986.

BECATTINI, G. Le district industriel: milieu créatif. Espace et Sociétés, n. 66-67, p. 147-164, 1981.

BIRD, Special Economic Zones: Performance, lessons learned, and implications for zone development. The World Bank Group: Nova York, 2008.

BIT, Rapport sur l'Initiative focale concernant les zones franches d'exportation (ZFE): dernières tendances et orientations dans les ZFE. Commission de l'emploi et de la politique sociale: Genève, 2008.

BIT, EMPLOYMENT AND SOCIAL POLICY IN RESPECT OF EXPORT PROCESSING ZONES EPZS. Geneva: International Labour Office - Governing Body/ Committee on Employment and Social Policy, 2003.

BLANC. A. et al. Exploitation des données textuelles. In: THIERTART, R. A. (Org.). Méthodes de Recherche en Management, 4 ed. Dunod: Paris, 2014.

BOSCHMA, R. A. A Proximity and Innovation: A Critical Assessment. Regional Studies, v. 39, n. 1, p. 61-74, 2005.

BRAGA, H. Nordeste: estratégias de desenvolvimento regional - discussão sobre ZPEs. Fórum BNB de Desenvolvimento: Nordeste: estratégias de desenvolvimento regional. Anais... Fortaleza. CE, 2006.

BRENNER, T. Cognitive Learning and the Emergence of Cooperation: An Simulation Approach. Computing in Economics and Finance. Society for Computational Economics, 2004.

CAMAGNI, R. Innovation networks, Spatial perspectives. Bellhaven Press: London/New York, 1991.

CHESBROUGH, H. Open Innovation: The New Imperative for Creating and Profiting from Technology. Boston: Harvard Business School Press, 2003. 
COOKE, P. Regional innovation systems, clusters, and the knowledge economy. Industrial and Corporate Change, v. 10, n. 4, p. 945-974, 2001.

DAUMAS, J. C. Districts industriels: du concept à l'histoire. Revue économique, v. 58, n. 1, p. 131-152, 2007.

DAVID, A. Logique, épistémologie et méthodologie en Sciences de gestion: trois hypothèses revisitées. In: DAVID, A.; HATCHUEL, A.; LAUFER, R. Les nouvelles fondations des sciences de gestion. Paris: Vuibert, 2000.

DORNIER, P. ; FENDER, M. La logistique globale et le supply chain management. GroupeEyrolles: Paris, 2009.

FURTADO, C. Uma política de desenvolvimento econômico para o Nordeste - GTDN. Revista Econômica do Nordeste, Fortaleza: BNB, v. 28, n. 4, p. 387-432, 1997.

GALVÃO, O. J. A. Políticas regionais na União Europeia e lições para o Brasil. Fortaleza: Banco do Nordeste do Brasil, 2010.

GARCIA, J. R.; COSTA, A. J. D. Sistemas produtivos locais: uma revisão da literatura. Seminário de gestão de negócios, 2005.

GARNSEY, E.; LONGHI, C. High technologylocationsandglobalisation: converse paths, common processes. InternationalJournalof Technology Management, v. 28, n. 3, 4, 5 e 6, p. 336-355, 2004.

GAROFOLI, G. Local development in Europe - theoretical models and international comparisons. European Urban and Regional Studies, p. 225-239, 2002.

GERTLER, M.S. A cultural economic geography of production: are we learning by doing? In: ANDERSONK. et al. (Org.) The Handbook of Cultural Geography. London: Sage, p. 131-146, 2003.

GIBBON, P. ; JONES, S.; THOMSEN, L. An assessment of the impact of Export Processing Zones and an identification of appropriate measures to support their development. Copenhagen: Danish Institute for International Studies, 2008.

GIPOULOUX, F. Hong Kong, Taiwan et Shanghai: Plate-formes logistiques rivales du corridor maritime de l'Asie de l'est. Perspectives Chinoises, n. 62, p. 4-12, 2000. 
GIROUX, N. L'étude de cas. In: GIORDANO, Y. Conduire un projet de recherche: Une perspective qualitative. Editions EMS: Colombelles, p. 42-84, 2003.

GREMAUD, A. P. ; VASCONCELLOS, M. A. S.; TONETO JÚNIOR, R. Economia brasileira contemporânea. 7. ed. São Paulo: Atlas, 2012.

HUBERMAN, A. M. ; MILLES, M.B. Analyse des données qualitatives un recueil de nouvelles méthodes. Bruxelles De Boeck Université, 2003.

HUET, F. ; LAZARIC, N. Capacités d'absorption et d'interaction: une étude de la coopération des PME françaises. Revue d'Économieindustrielle, n. 121, p. 65-84, 2008.

JAYANTHAKUMARAN, K. Benefit-cost appraisals of Export Processing Zones: a survey of the literature. Development Policy Review, v. 21, n. 1, p. 51-65, 2003.

KOGUT, B. The Network as Knowledge: Generative Rules and the Emergence of Structure. Strategic Management Journal, v. 21, p. 405-425, 2000.

KRUGMAN, P. R.; OBSTFELD, M. Economialnternacional. Teoria e Política. Tradução: Celina Martins RamaIho Laranjeira. 5. ed. São Paulo: Pearson Education do Brasil, 2001.

LAURIOL, J. et al. Stratégies, espaces et territoires. Revue Française de Gestion, v. 4, n. 184, 2008.

LOILIER, T. Innovation et territoire, le rôle de la proximité géographique ne doit pas être surestimé. Revue française de gestion, n. 200, p. 15-35, 2010.

LUCAS, R. Making a Miracle. Econometrica, v. 61, p. 251-72, 1993.

MALMBERG, A.; MASKELL,P. The Elusive Concept of Localisation Economies: Towards a Knowledge-Based Theory of Spatial Clustering. Environment and Planning A, v. 34, p. 429-449, 2002.

MALMBERG, A.; POWER, D. (How) Do (firms in) clusters create knowledge? Industry and Innovation, v. 12, p. 409-431, 2005.

MARKUSEN, A. et al.High Tech America: The What, How, Where and Why of the Sunrise Industries. Boston and London: Allen \&Unwin, 1986. 
. Áreas de atração de investimentos em um espaço econômico cambiante: uma tipologia de distritos industriais. Nova Economia: Belo Horizonte, v. 5, n. 2, p. 9-44, 1995.

Sticky Places in Slippery Space: A Typology on Industrial Districts. EconomicGeography, v. 72, p. 293-313, 1996.

MARSHALL, A. Princípios de Economia. Coleção os Economistas. São Paulo: Nova Cultural, 1988.

MILBERG, W.; AMENGUAL, M. Développement économique et conditions de travail dans les zones

franches d'exportation: un examen des tendances. Organisationinternationale du Travail: Genève, 2008.

MORGAN, K. The Learning Region: Institutions, Innovation and Regional Renewal. Regional Studies, v. 31, p. 491-503, 1997.

NAHAPIET, J.; GHOSHAL,S. Social Capital, Intellectual Capital, and the Organizational Advantage. Academy of Management Review, v. 23, n. 2, p. 242-266, 1998.

PORTER, M. The Competitive Advantage of Nations. London Macmillan, 1990.

. Clusters and the new economics competition. Harvard Business Review,1998.

QUIVY, R.; VAN CAMPENHOULDT, L. Manuel de recherche en sciences sociales.Dunod: Paris, 1995.

RALLET, A.; TORRE, A. Proximity and localization. Regional Studies, v. 39, n. 1, p. 47-60, 2005.

RYCHEN, F.; ZIMMERMANN, J. B. Clusters in the global knowledge based economy: knowledge gatekeepers and temporary proximity. Regional Studies, v. 42, n. 26, 2006.

SCHMITZ, H. Eficiência coletiva: caminho de crescimento para a indústria de pequeno porte. Ensaios FEE, Porto Alegre, v. 18, n. 2, p. 164-200, 1997.

SCHUMPETER, J. A Teoria do Desenvolvimento Econômico. São Paulo: Nova Cultural, 1988.

SNOW, C.; THOMAS, J. B. Field research methods in strategic management: contributions to theory building and testing. Journal of Management Studies, n. 31, p. 457-480, 1994.

TORRE, A.; BEURET, J. E. Proximitéterritoriales. Economica, Paris, 2012. 
TEECE, D. J. Explicating dynamic capabilities: the nature and microfoundations of (sustainable) enterprise performance. Strategic Management Journal, v. 28, p. 1319-1350, 2007.

TEECE, D.; PISANO, G.; SHUEN, A. Dynamic capabilities and strategic management. Strategic Management Journal, v. 18, p. 509-533, 1997.

THIETART, R. Méthodes de recherche en management.Dunod, Paris, 2003.

VIANNA, P. J. R. A importância de uma ZPE para a economia cearense. Carta Econômica, n. 1, 2010.

VIRGILL, N. A. V. Export Processing Zones: tools of development or reform delay? Fairfax, VA, George Mason University, School of Public Policy, 2009.

VISSER, E. J. The complementary dynamic effects of clusters and networks. IndustryandInnovation, v. 16, n. 2, p. 167-195, 2009. 